\title{
Circulating microRNAs and Kallikreins before and after Radical Prostatectomy: Are They Really Prostate Cancer Markers?
}

\author{
Maria Giulia Egidi, ${ }^{1}$ Giovanni Cochetti, ${ }^{1}$ Maria Rita Serva, ${ }^{1}$ Gabriella Guelfi, \\ Danilo Zampini, ${ }^{2}$ Luca Mechelli, ${ }^{2}$ and Ettore Mearini ${ }^{1}$ \\ ${ }^{1}$ Department of Medical-Surgical Sciences and Public Health, Faculty of Medicine and Surgery, University of Perugia, \\ Loc. S. Andrea delle Fratte, 06156 Perugia, Italy \\ ${ }^{2}$ Department of Biopathological Science and Hygiene of Food and Animal Production, Faculty of Veterinary Medicine, \\ University of Perugia, Via San Costanzo 4, 06126 Perugia, Italy
}

Correspondence should be addressed to Giovanni Cochetti; giovannicochetti@libero.it

Received 10 May 2013; Revised 9 August 2013; Accepted 23 August 2013

Academic Editor: Romonia Renee Reams

Copyright (C) 2013 Maria Giulia Egidi et al. This is an open access article distributed under the Creative Commons Attribution License, which permits unrestricted use, distribution, and reproduction in any medium, provided the original work is properly cited.

The aim of our study was to monitor serum levels of two miRNAs (miR-21 and miR-141) and three KLKs (hK3/PSA, hK11, and $\mathrm{hK} 13$ ) before and 1, 5, and 30 days after radical prostatectomy, in order to characterize their fluctuations after surgery. 38 patients with prostate cancer were included. miR-21 and miR-141 were quantified through real-time PCR, while ELISA assays were used to quantify hK3 (PSA), hK11, and hK13. Both miR-21 and miR-141 showed a significant increase at the 5th postoperative day, after which a gradual return to the preoperative levels was recorded. These findings suggest that miR-21 and miR-141 could be involved in postsurgical inflammatory processes and that radical prostatectomy does not seem to alter their circulating levels. Postoperative serum kallikreins showed a significant decrease, highlighting the potential usefulness of kallikreins apart from PSA as potential prostate cancer markers.

\section{Introduction}

Prostate cancer $(\mathrm{PCa})$ is the most common male tumor in Europe and USA. The introduction of prostate-specific antigen (PSA, i.e., hK3) in the diagnostic management has allowed an earlier detection and thus the possibility to treat more cancers at a precocious and localized stage, improving the cure rates. Kallikreins are a family of peptidases widely expressed in various tissues, and they rule various physiological events, such as blood pressure homeostasis, skin homeostasis, and semen liquefaction. The proposal of kallikreins besides PSA as cancer biomarkers has been already reported, on the basis of the alterations in expression of many members of this family in several cancers [1-3].

microRNAs (miRNAs) are small noncoding singlestranded RNAs controlling the expression of protein-coding transcripts: each miRNA targets several genes at the posttranscriptional level [4]. About 10-30\% of all human genes are regulated by miRNAs [5]. In the last decade, microRNAs have been studied as potential markers for almost every type of cancer [6]: miRNAs locate at cancer-related genomic regions or in fragile sites, and this feature suggests their potential role in tumorigenesis [7]. In 2007, Porkka performed the first profiling of miRNA involved in prostate cancer [8]. miRNAs and KLKs are characterized by a high stability in the serum and for this reason they are both ideal candidates for noninvasive assays.

The first end point of this study was to compare preoperative expression levels of three kallikreins (hK3/PSA, hK11, and hK13) and 2 miRNAs (miR-21, miR-141) with postoperative ones, in order to evaluate if a specific correlation between prostate cancer and these markers exists. The second aim was to evaluate their diagnostic power comparing the preoperative values in prostate cancer patients with healthy ones.

\section{Materials and Methods}

2.1. Experimental Design. This study was approved by the Institutional Internal Review Board of Santa Maria Hospital, 


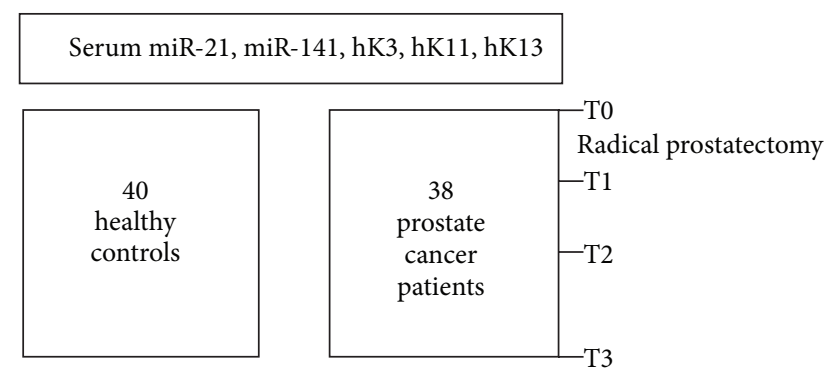

FIgURE 1: Overview of the experimental design. T0: presurgical phase; T1: 1 day after surgery; T2: 5 days after surgery; T3: 30 days after surgery; C: control.

TABLE 1: Demographic characteristics of the patients enrolled in the present study.

\begin{tabular}{lc}
\hline Clinical parameters & PCa \\
Median age (range) & $62(54-63 \mathrm{ys})$ \\
Median PSA (range) & $5.55(3.11-9 \mathrm{ng} / \mathrm{mL})$ \\
Clinical stage & \\
T1c & $21(55.3 \%)$ \\
T2a & $6(15.8 \%)$ \\
T2b & $3(7.9 \%)$ \\
T2c & $8(21 \%)$ \\
Pathological Gleason score & \\
$6(3+3)$ & $20(52.6 \%)$ \\
$7(3+4)$ & $2(5.3 \%)$ \\
$7(4+3)$ & $12(31.6 \%)$ \\
$8(4+4)$ & $4(10.5 \%)$ \\
Lymph node involvement & $6(15.8 \%)$ \\
Pathological stage & \\
T2a & $6(15.8 \%)$ \\
T2b & $2(5.3 \%)$ \\
T2c & $24(63.1 \%)$ \\
T3a & $4(10.5 \%)$ \\
T3b & $2(5.3 \%)$ \\
\hline
\end{tabular}

Terni. 38 patients who undergone radical prostatectomy for localized prostate cancer were enrolled consecutively from September 2011 to April 2012. 40 subjects were selected as healthy controls: their mean age was 39 years, mean PSA was $0.56 \mathrm{ng} / \mathrm{mL}$, and they have no history of prostatitis or other urologic pathologies. The demographic characteristics of all prostate cancer patients are reported in Table 1, and the experimental design is shown in Figure 1. Expression levels of miR-21 and miR-141 were measured through real-time PCR, while ELISA assays were conducted on the same serum samples to quantify hK3 (PSA), hK11, and hK13. In prostate cancer patients, serum levels of miRNAs (miR-21 and miR141) and kallikreins (hK3, hK11, and hK13) were measured at four time points: 1 day before surgery (T0) and 1st (T1), 5th (T2), and 30th (T3) postoperative days (Figure 1).

2.2. Serum Collection and Storage. Serum samples were all obtained from subjects subscribing informed consent. All patients underwent fasting blood withdrawal at one day before surgery (T0) without receiving any drug treatment. Blood was withdrawn into Vacuette Z Serum Sep Clot Activator (Greiner Bio-One). Collection tubes were gently inverted five times to ensure full contact with inner procoagulant surface, and coagulation process was allowed maintaining vacuette for 30 minutes at RT. After centrifugation $(2000 \times \mathrm{g}$, $10 \mathrm{~min}$ ), aliquots were immediately stored at $-80^{\circ} \mathrm{C}$ until use.

2.3. RNA Isolation. $200 \mu \mathrm{L}$ of serum was used for the extraction of total RNA with Total Purification Kit (Norgen Biotek Corp., Ontario, Canada), following the instructions for plasma and serum, with minor modifications. Total RNA was quantified by Qubit RNA assay (Life technologies) and stored at $-20^{\circ} \mathrm{C}$ until use.

2.4. Reverse Transcription. $4 \mu \mathrm{L}$ of purified RNA ( $20 \mathrm{ng}$ ) was reverse-transcribed using the miRCURY LNA Universal RT miR PCR, polyadenylation, and cDNA synthesis kit (Exiqon). RNA spike-in control (UniSp6 RNA template, provided with the cDNA synthesis kit) was introduced in RT mix immediately before retrotranscription in a $20 \mu \mathrm{L}$ cDNA reaction and served to monitor cDNA synthesis and PCR efficiency.

2.5. Real-Time PCR. Primers were designed based on mature miRNA sequence (miRCURY LNA specific PCR primer set, Exiqon system). Each sample was run in triplicate, and the results were averaged; no-template controls were included in the analysis. Exiqon miRCURY LNA Universal RT microRNA PCR SYBR Green master mix has been used to amplify cDNAs. All PCR reactions were performed on a Bio-Rad iCycler Real-Time PCR system. Three miRNAs (miR-93, -103, -191) were tested for normalization according to the manufacturer's recommendations for serum/plasma applications [9].

2.6. ELISA Assay of $h K 11$ and $h K 13.250 \mu \mathrm{L}$ of serum was used for measurement of hK11 and hK13 with sandwich ELISA (human KLK-11 and KLK-13 pair sets ELISA kits, Sino Biological Inc., Beijing, China). ELISA microplates were separately coated with $100 \mu \mathrm{L}$ of diluted of affinity-purified rabbit $\mathrm{mAbs}$ anti-hK11 or anti-hK13 $(2 \mu \mathrm{g} / \mathrm{mL}$ in $5 \mathrm{mM}$ carbonatebicarbonate), incubated overnight at $4{ }^{\circ} \mathrm{C}$, and washed three times with TBS containing Tween $200.05 \%$ (300 $\mu \mathrm{L} /$ well). Solid phase blocking was performed adding TBST containing BSA $2 \%(300 \mu \mathrm{L} /$ well $)$ and incubating $60 \mathrm{~min}$ at RT. Wells were then washed three times, and $100 \mu \mathrm{L} /$ well of serum samples was incubated for $60 \mathrm{~min}$ at RT. Plates were washed again as above, and $100 \mu \mathrm{L} /$ well of anti-rabbit IgG antibody HRP labeled $(1 \mu \mathrm{g} / \mathrm{mL})$ was dispensed and incubated for $60 \mathrm{~min}$ at RT. Plates were once more washed, and $100 \mu \mathrm{L} /$ well of TMB solution (Sigma) was added and incubated for $20 \mathrm{~min}$, before stopping with $100 \mu \mathrm{L} /$ well of $\mathrm{H}_{2} \mathrm{SO}_{4} 1 \mathrm{~N}$ and measuring $\mathrm{OD}$ at $450 \mathrm{~nm}$ on a microplate reader (Infinite 200, Tecan, Männedorf, Switzerland). hK11 and hK13 serum levels were referred to a standard curve of recombinant human kallikreins 11 and 13. 
2.7. Total PSA Assay. Total serum PSA measurements were performed through Advia Centaur automated system (Siemens Health Care Diagnostics, Victoria, Australia). The two-site sandwich immunoassay consists of polyclonal goat anti-PSA antibody and a monoclonal mouse anti-PSA antibody.

2.8. Statistical Analysis. Tukey's Multiple Comparison Test was used to compare the serum samples obtained before and after surgery and to compare the difference in the serum miRNA and hKs expression between the cancer group and the healthy control group. The significance was set as $P \leq$ 0.05 .

Receiver Operating Characteristic (ROC) curve analysis was performed to estimate the diagnostic accuracy of miR21, miR-141, hK11, and hK13. Logistic regression analysis was performed to evaluate the diagnostic accuracy of the combination of miRNAs.

\section{Results}

3.1. Serum hK3, hK11, and $h K 13$ before and after Radical Prostatectomy. hK11 levels significantly decreased after surgery (T0 $>$ T1, $P<0.05)$ and remained substantially unmodified at T2 and T3 $(P>0.05)$ (Table 2$)$. The marked decreased of hK11 at the first postoperative day resembled that of PSA (Figure 2). Contrary to PSA which progressively decreased to finally fall down to zero at T3 (Figure 3), hK11 showed a slight increase at T3, although this was not statistically significant $(P>0.05)$.

In contrast, serum hK13 levels significantly increased at T1 (T0 $<$ T1, $P<0.05)$ and finally stabilized at lower levels with respect to preoperative values (T2 $<\mathrm{T} 0, P<0.05$ ) (Figure 2 ). As seen for hK11, hk13 did not decrease further at T3 (T2 versus T3, $P>0.05$ ).

3.1.1. Comparison of Serum hK11 and hK13 between Prostate Cancer Patients before Surgery (T0) and Healthy Controls (C). Serum levels of hK11 and hK13 were significantly higher $(P<0.05)$ in serum from prostate cancer patients at T0 with respect to healthy controls (Figure 4 and Table 3 ), similarly to PSA (Figure 5).

Serum levels of hK11 and hK13 in control group were also compared with values obtained from prostate cancer group at postoperative sampling times (T1, T2, and T3, see Table 4). Only serum levels of hK13 in patients at the 1st day after surgery differed significantly from controls.

3.2. Serum miR-21 and miR-141 before and after Radical Prostatectomy. For real-time PCR applications, miR-93 exhibited the lowest coefficient of variation in the assay and was chosen as reference gene. The normalized data against miR-93 levels were reported as the mean value $\pm \mathrm{SD}$.

Serum levels of miR-21 and miR-141 were analyzed at T0, T1, T2, and T3 (Table 5 and Figure 6). Both miR-21 and miR141 increased significantly at the fifth postoperative day (T0< T2, $P<0.01$ and $P<0.001$, resp.). At T3, serum miR-21 and
miR-141 were not significantly different from preoperative levels (T0 $=\mathrm{T} 3, P>0.05)$.

3.2.1. Comparison of Serum miR-21 and miR-141 between Patients (T0) and Healthy Controls (C). In prostate cancer patients serum levels of miR-21 preoperatively were not significantly different from healthy controls $(P>0.05)$. On the contrary, serum miR-141 preoperative levels were significantly lower $(P<0.05)$ than healthy controls (Figure 7 and Table 6).

Circulating levels of miR-21 and miR-141 from controls were also compared with prostate cancer group at postoperative sampling times (T1, T2, and T3). Results are shown in Table 7. For miR-21, statistically significant differences were obtained when $\mathrm{C}$ was compared with T2 $(P<0.01)$. Comparisons of $\mathrm{C}$ with $\mathrm{T} 1$ and $\mathrm{T} 2$ did not reach significance (C versus T1 and $\mathrm{C}$ versus T2, $P>0.05$ ). Serum levels of miR141 in control group were significantly different from those of patients only at the 30th day after surgery ( $C$ versus $\mathrm{T} 3$, $P<0.05$; $\mathrm{C}$ versus $\mathrm{T} 1$ and $\mathrm{C}$ versus T2, $P>0.05$ ).

3.3. Evaluation of Diagnostic Accuracy of miR-21, miR-141, $h K 11$, and $h K 13$. The diagnostic accuracy of miR-21, miR141, hK11, and hK13 was evaluated using Receiver Operating Characteristic (ROC) curve analysis. As shown in Figure 8, serum miR-21 displayed the lowest ability (AUC $=0.597, P>$ 0.05 ) to differentiate between prostate cancer patients and healthy controls, whereas miR-141 reached an AUC of 0.811 $(P<0.0001)$. Serum hK13 showed the highest diagnostic performance $(\mathrm{AUC}=0.997, P<0.0001)$, followed by hK11 (AUC $=0.994, P<0.0001)$.

Logistic regression analysis was performed to evaluate the probability that the combination of miR-141 and miR-21 could discriminate prostate cancer patients from healthy controls in a better way than miR-141 alone. Area under the curve was 0.811 (which was equal to miR-141 alone) and sensitivity was lower than miR-141 (68.42\% versus $78.9 \%)$, while specificity increased slightly ( $85 \%$ versus $82.5 \%$ ).

\section{Discussion}

4.1. Prostate Cancer Beyond PSA: Postoperative Serum Levels of $h K 11$ and $h K 13$. The main diagnostic tools to detect prostate cancer include digital rectal examination, serum PSA, and transrectal ultrasound guided biopsy. PSA is a quite accurate diagnostic test, but its specificity is too low because PSA is a prostate-specific but not a prostate cancerspecific marker: for this reason, those biopsies requested for altered PSA levels are often negative. When PSA is ranged between 4.0 and $9.9 \mathrm{ng} / \mathrm{mL}$, the first prostate biopsy is positive only up to $37 \%$ [10]. PSA belongs to the genetic family of kallikreins, a group of serine proteases widely expressed in various tissues and involved both in many physiological and in pathological processes: the alteration in their expression is related to the onset of various human diseases [11-13]. Since they are circulating proteins, kallikreins are detectable in human body fluids, such as serum, and may be used as molecular assays characterized by a low invasiveness 
TABLE 2: ANOVA showing significance values of hK11 and hK13 for each comparison.

\begin{tabular}{|c|c|c|c|c|c|c|}
\hline \multirow{2}{*}{ Tukey's multiple comparison test } & \multirow{2}{*}{ Groups } & \multirow{2}{*}{ Mean difference } & \multirow{2}{*}{$q$} & \multirow{2}{*}{$P$ value } & \multicolumn{2}{|c|}{$95 \% \mathrm{CI}$} \\
\hline & & & & & Lower & Upper \\
\hline \multirow{6}{*}{ hK11 } & T0 versus T1 & 162.1 & 7.51 & $P<0.05$ & 76.28 & 248.0 \\
\hline & $\mathrm{T} 0$ versus $\mathrm{T} 2$ & 174.7 & 8.09 & $P<0.05$ & 88.86 & 260.6 \\
\hline & T0 versus T3 & 115.5 & 5.35 & $P<0.05$ & 29.65 & 201.4 \\
\hline & $\mathrm{T} 1$ versus $\mathrm{T} 2$ & 12.58 & 0.59 & $P>0.05$ & -73.27 & 98.43 \\
\hline & $\mathrm{T} 1$ versus $\mathrm{T} 3$ & -46.63 & 2.16 & $P>0.05$ & -132.5 & 39.22 \\
\hline & $\mathrm{T} 2$ versus $\mathrm{T} 3$ & -59.21 & 2.74 & $P>0.05$ & -145.1 & 26.64 \\
\hline \multirow{6}{*}{ hK13 } & T0 versus $\mathrm{T} 1$ & -111.0 & 9.00 & $P<0.05$ & -160.0 & -61.99 \\
\hline & T0 versus $\mathrm{T} 2$ & 81.60 & 6.62 & $P<0.05$ & 32.59 & 130.6 \\
\hline & T0 versus T3 & 62.70 & 5.08 & $P<0.05$ & 13.69 & 111.7 \\
\hline & $\mathrm{T} 1$ versus $\mathrm{T} 2$ & 192.6 & 15.62 & $P<0.05$ & 143.6 & 241.6 \\
\hline & $\mathrm{T} 1$ versus $\mathrm{T} 3$ & 173.7 & 14.09 & $P<0.05$ & 124.7 & 222.7 \\
\hline & $\mathrm{T} 2$ versus T3 & -18.90 & 1.53 & $P>0.05$ & -67.91 & 30.11 \\
\hline
\end{tabular}

T0: preoperative time; T1: 1st postoperative day; T2: 5 th postoperative day; T3: 30th postoperative day.

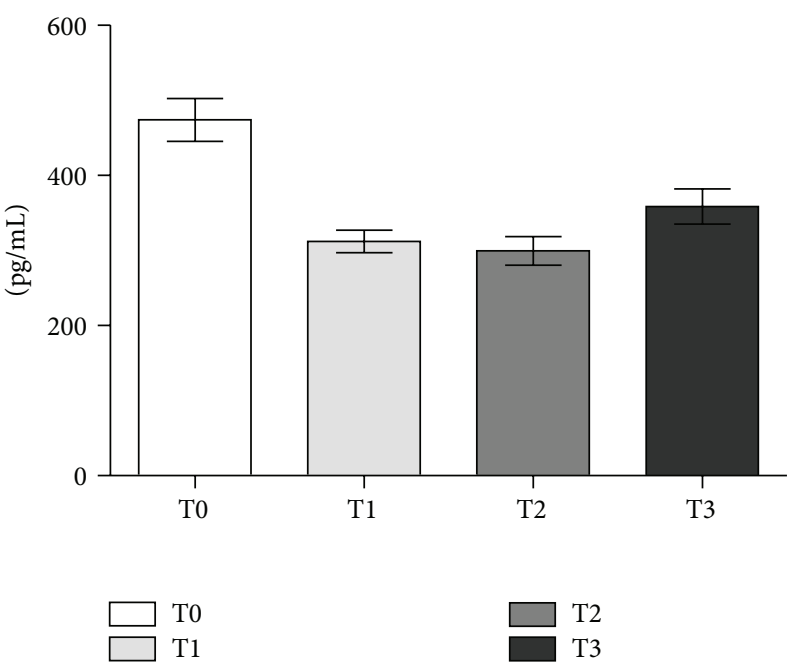

(a)

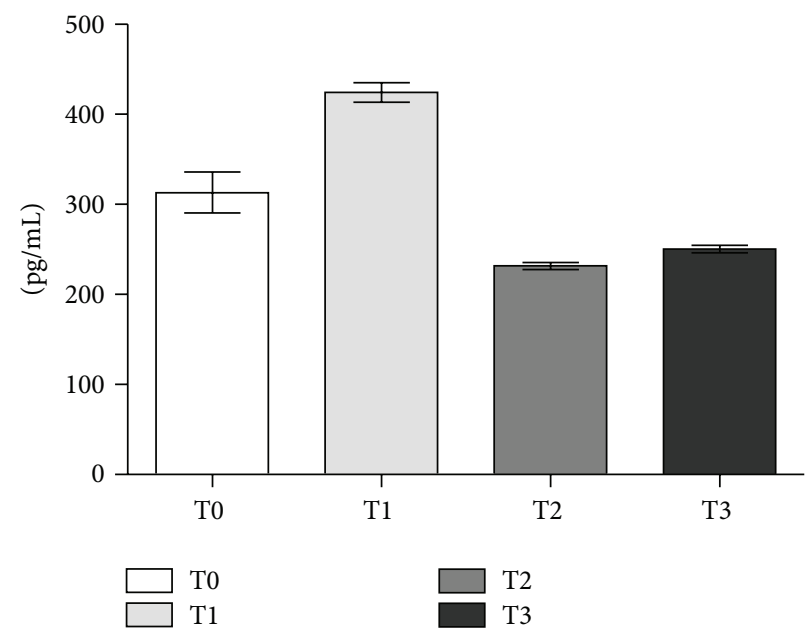

(b)

FIGURE 2: hK11 (Panel a) and hK13 (Panel b) levels (pg/mL \pm SE) by ELISA in sera from patients with localized prostate cancer. T0: preoperative time; T1: 1st postoperative day; T2: 5 th postoperative day; T3: 30 th postoperative day.

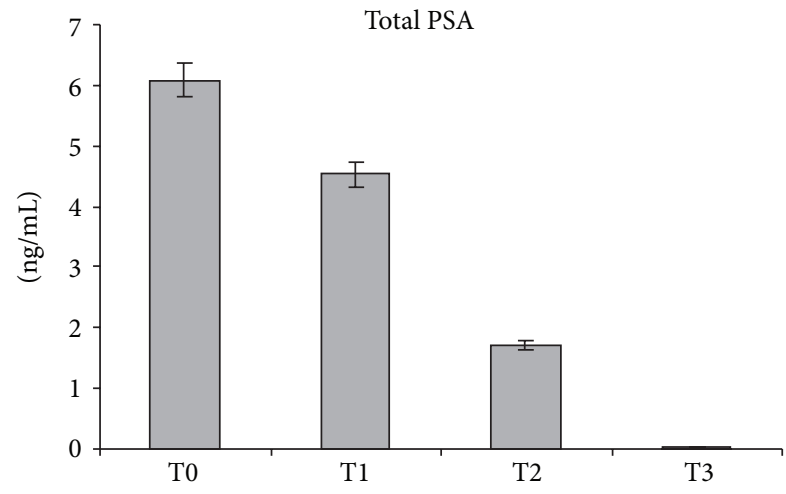

FIGURE 3: PSA levels expressed as $\mathrm{ng} / \mathrm{mL} \pm \mathrm{SE}$. T0: preoperative time; T1: 1st postoperative day; T2: 5 th postoperative day; T3: 30 th postoperative day. and high accuracy. hK2 has been quite recently assayed for its utility in preoperative staging of localized prostate cancer [14]. hK2 was showed to improve the power of total, free, and intact PSA in predicting biopsy outcome in men with PSA levels [15]. Quite recently, the involvement of other kallikreins apart from PSA/hK3 and hK2 in prostate cancerogenesis has been progressively clarified: KLK11 was recently proposed as a new prognostic marker for PCa [16]. The KLK13 protein shares $51 \%$ amino acid identity with KLK11, and it is primarily expressed in mammary gland, prostate, salivary gland, and testis. KLK13 gene was found to be regulated by steroid hormones in a human breast cancer cell line so that its expression is an independent favorable prognostic marker for breast carcinoma [17].

PSA is the unique kallikrein whose postsurgical kinetics has been studied: to our knowledge, this is the first report 
TABLE 3: Statistical analysis of serums hK11 and hK13.

\begin{tabular}{|c|c|c|c|c|c|c|}
\hline \multirow{2}{*}{ Tukey's multiple comparison test } & \multirow{2}{*}{ Groups } & \multirow{2}{*}{ Mean difference } & \multirow{2}{*}{$q$} & \multirow{2}{*}{$P$ value } & \multicolumn{2}{|c|}{$95 \% \mathrm{CI}$} \\
\hline & & & & & Lower & Upper \\
\hline hK11 & C versus T0 & -176.8 & 6.532 & $P<0.05$ & -284.5 & -69.23 \\
\hline hK13 & $\mathrm{C}$ versus T0 & -101.2 & 6.547 & $P<0.05$ & -162.6 & -39.76 \\
\hline
\end{tabular}

T0: preoperative time; C: control.

TABLE 4: ANOVA showing significance values of hK11 and hK13 for each comparison.

\begin{tabular}{lccccrr}
\hline \multirow{2}{*}{ Tukey's multiple comparison test } & Groups & Mean difference & $q$ & P value & Lower & Upper \\
\hline \multirow{3}{*}{ hK11 } & C versus T1 & -14.72 & 0.544 & $P>0.05$ & -122.3 & -92.90 \\
& C versus T2 & -2.136 & 0.079 & $P>0.05$ & -109.8 & 105.5 \\
& C versus T3 & -61.35 & 2.266 & $P>0.05$ & -169.0 & 26.27 \\
\hline \multirow{3}{*}{ hK13 } & C versus T1 & -212.2 & 13.73 & $P<0.05$ & -273.6 & -150.8 \\
& C versus T2 & -19.60 & 1.268 & $P>0.05$ & -81.04 & 41.84 \\
& C versus T3 & -38.50 & 2.491 & $P>0.05$ & -99.94 & 22.94 \\
\hline
\end{tabular}

C: control; T1: 1st postoperative day; T2: 5 th postoperative day; T3: 30 th postoperative day.

TABLE 5: ANOVA showing significance values of miR-21 and miR-141 for each comparison.

\begin{tabular}{|c|c|c|c|c|c|c|}
\hline \multirow{2}{*}{ Tukey's multiple comparison test } & \multirow{2}{*}{ Groups } & \multirow{2}{*}{ Mean difference } & \multirow{2}{*}{$q$} & \multirow{2}{*}{$P$ value } & \multicolumn{2}{|c|}{$95 \% \mathrm{CI}$} \\
\hline & & & & & Lower & Upper \\
\hline \multirow{6}{*}{ miR-21 } & T0 versus $\mathrm{T} 1$ & -0.255 & 0.75 & $P>0.05$ & -1.592 & 1.082 \\
\hline & T0 versus $\mathrm{T} 2$ & 1.687 & 4.98 & $P<0.01$ & 0.350 & 3.024 \\
\hline & T0 versus T3 & 0.498 & 1.47 & $P>0.05$ & -0.839 & 1.835 \\
\hline & $\mathrm{T} 1$ versus $\mathrm{T} 2$ & 1.942 & 5.73 & $P<0.01$ & 0.605 & 3.279 \\
\hline & $\mathrm{T} 1$ versus $\mathrm{T} 3$ & 0.753 & 2.22 & $P>0.05$ & -0.584 & 2.090 \\
\hline & $\mathrm{T} 2$ versus $\mathrm{T} 3$ & -1.189 & 3.51 & $P>0.05$ & -2.526 & 0.148 \\
\hline \multirow{6}{*}{ miR-141 } & T0 versus $\mathrm{T} 1$ & 0.666 & 1.75 & $P>0.05$ & -0.835 & 2.167 \\
\hline & $\mathrm{T} 0$ versus $\mathrm{T} 2$ & 2.855 & 7.51 & $P<0.001$ & 1.354 & 4.356 \\
\hline & T0 versus T3 & -0.237 & 0.62 & $P>0.05$ & -1.738 & 1.264 \\
\hline & $\mathrm{T} 1$ versus $\mathrm{T} 2$ & 2.189 & 5.76 & $P<0.01$ & 0.688 & 3.690 \\
\hline & $\mathrm{T} 1$ versus $\mathrm{T} 3$ & -0.903 & 2.37 & $P>0.05$ & -2.404 & 0.598 \\
\hline & $\mathrm{T} 2$ versus $\mathrm{T} 3$ & -3.092 & 8.13 & $P<0.001$ & -4.593 & -1.591 \\
\hline
\end{tabular}

T0: preoperative time; T1: 1st postoperative day; T2: 5 th postoperative day; T3: 30 th postoperative day.

TABLE 6: Statistical analysis showing significance values of miR-21 and miR-141.

\begin{tabular}{|c|c|c|c|c|c|c|}
\hline \multirow{2}{*}{ Tukey's multiple comparison test } & \multirow{2}{*}{ Groups } & \multirow{2}{*}{ Mean difference } & \multirow{2}{*}{$q$} & \multirow{2}{*}{$P$ value } & \multicolumn{2}{|c|}{$95 \% \mathrm{CI}$} \\
\hline & & & & & Lower & Upper \\
\hline miR-21 & $\mathrm{C}$ versus $\mathrm{T} 0$ & 0.197 & 0.59 & $P>0.05$ & -1.123 & 1.517 \\
\hline miR-141 & $\mathrm{C}$ versus T0 & -1.506 & 4.01 & $P<0.05$ & -2.988 & -0.024 \\
\hline
\end{tabular}

T0: preoperative time; C: control.

TABLE 7: ANOVA showing significance values of miR-21 and miR-141 for each comparison.

\begin{tabular}{lcccrrr}
\hline \multirow{2}{*}{ Tukey's multiple comparison test } & Groups & Mean difference & $q$ & P value & Lower & Upper \\
& & & -0.058 & 0.17 & $P>0.05$ & -1.378 \\
\multirow{3}{*}{ miR-21 } & C versus T1 & 1.884 & 5.63 & $P<0.01$ & 0.564 & 3.262 \\
& C versus T2 & 0.695 & 2.08 & $P>0.05$ & -0.625 & 2.015 \\
\hline \multirow{3}{*}{ miR-141 } & C versus T3 & -0.840 & 2.24 & $P>0.05$ & -2.322 \\
& C versus T1 & 1.349 & 3.59 & $P>0.05$ & -0.133 & 0.642 \\
& C versus T2 & -1.743 & 4.64 & $P<0.05$ & -3.225 & -0.261 \\
\hline
\end{tabular}

C: control; T1: 1st postoperative day; T2: 5th postoperative day; T3: 30th postoperative day. 


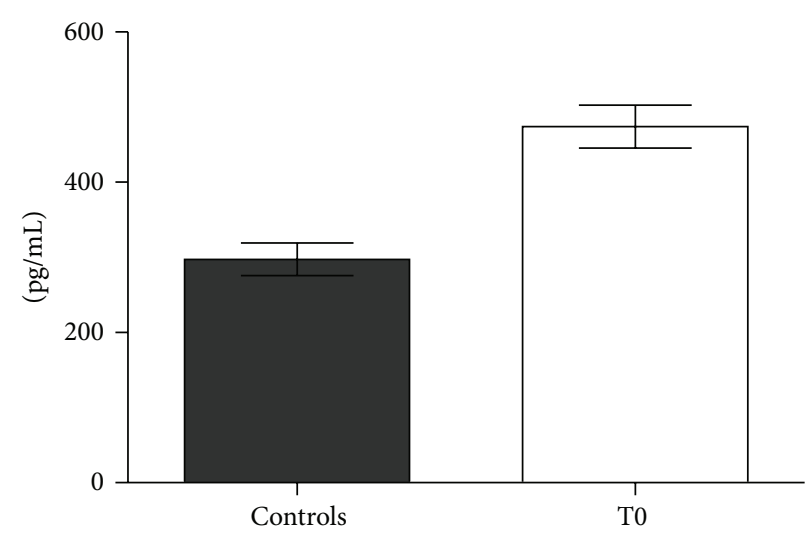

Controls $\mathrm{T} 0$

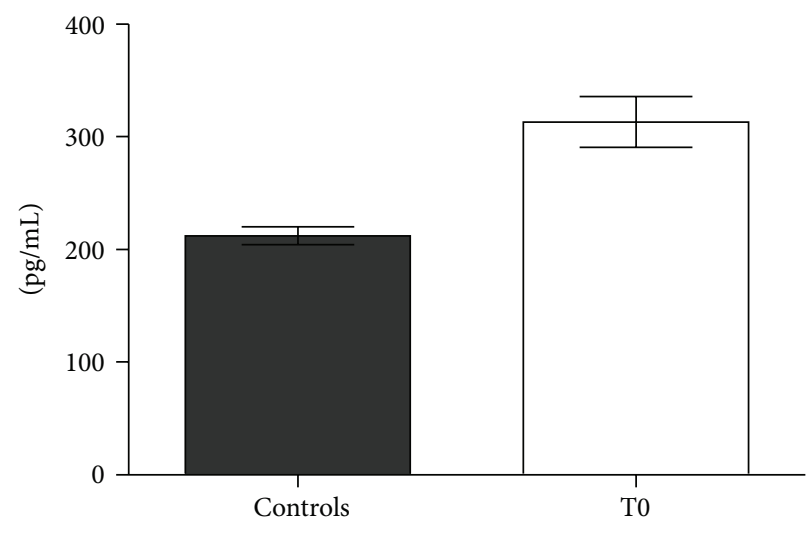

Controls T0

(a)

(b)

FIgURE 4: hK11 (Panel a) and hK13 (Panel b) levels (pg/mL \pm SE) by ELISA in sera from patients with localized prostate cancer. C: control; T0: preoperative time.

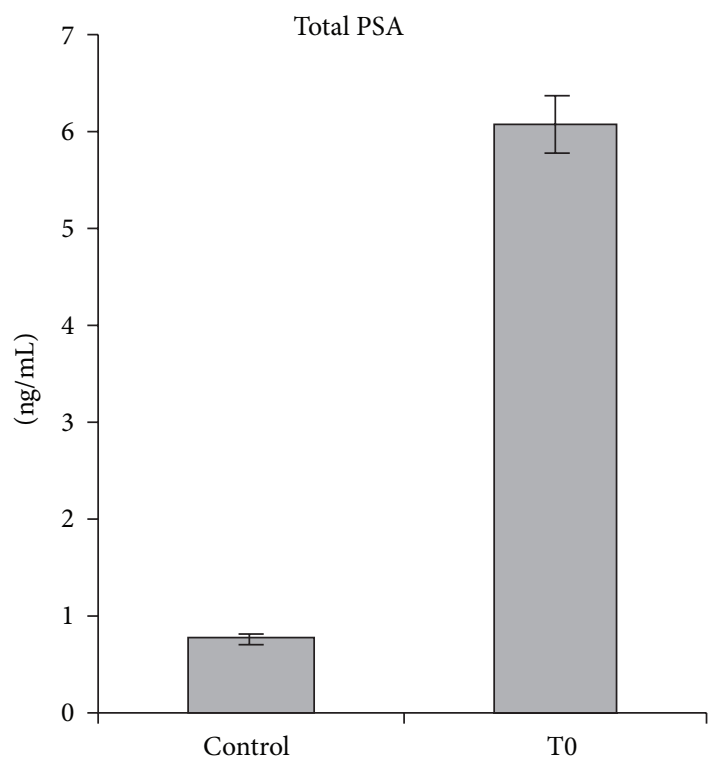

FIGURE 5: PSA levels expressed as $\mathrm{ng} / \mathrm{mL} \pm \mathrm{SE}$. C: control; T0: preoperative time.

describing postoperative changes in serum levels of other kallikreins at multiple times. Both hK11 and hK13 were significantly higher in prostate cancer patients before surgery and they significantly decreased after surgery. Serum hK13 showed a transient increase at the first day after surgery, suggesting an implication in inflammatory events, whereas serum hK11 immediately decreased after surgery. Both hK11 and $\mathrm{hK} 13$ stabilized at lower levels with respect to preoperative values, although they did not fall down to zero such as PSA, which became undetectable 30 days after surgery. hK11 even seemed to increase at the 30th day after radical prostatectomy, although comparisons of T3 with T2 or T1 were not statistically significant. These findings highlighted the direct correlation of these kallikreins to prostate cancer. This was confirmed by the significant difference of hK11 and hK13 serum levels in prostate cancer patients with respect to controls (T0 $>$ C, $P<0.05$ ). Serum hK11 and hK13 fluctuations after surgery appeared to have a strong correlation with prostate cancer, since their decrease to lower levels with respect to preoperative values resembles PSA postoperative decay curve.

4.2. Changes in Serums miR-21 and miR-141 after Radical Prostatectomy: Only a Matter of Inflammation? microRNA are progressively emerging as crucial regulators of gene expression, since they affect the tumorigenesis as oncogenes or oncosuppressors $[6,18-20]$. The intrinsic stability of miRNAs in human plasma/serum renders these molecules ideal candidates for the development of low invasive diagnostic assays [21]. The involvement of miRNAs in carcinogenesis has been reported elsewhere: this widespread interest on miRNAs led to the development of commercial cancer biomarker assays for pancreatic cancer versus pancreatitis [22], squamous versus nonsquamous lung cancer [23], and malignant pleural mesothelioma versus lung and pleura cancers [24]. miRNAs proved also to be effective in the identification of the unknown primitive cancer of metastasis [25]. Besides being involved in carcinogenesis, several studies have defined mammalian microRNAs as key regulators of the immune system. In fact, inflammation is able to regulate miRNA biogenesis [26].

miR-21 has been recognized as oncomir, and it has been demonstrated to target, among others, the following genes: tumor suppressor gene tropomyosin 1 (TPM1), programmed cell death 4 (PDC D4), maspin, phosphatase and tensin homolog (PTEN), and reversion-inducing cysteine-rich protein with kazal motifs (RECK) [26-29]. A recent study aimed 
T0
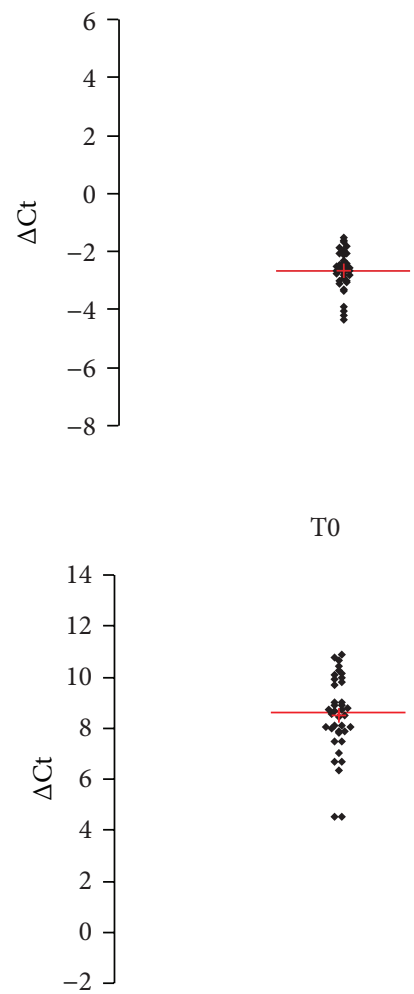

T0

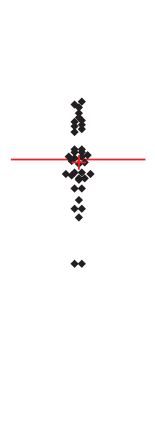

$\mathrm{T} 1$

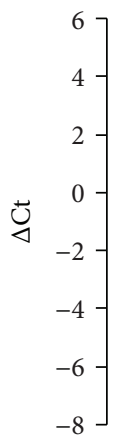

T1

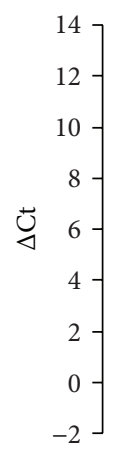

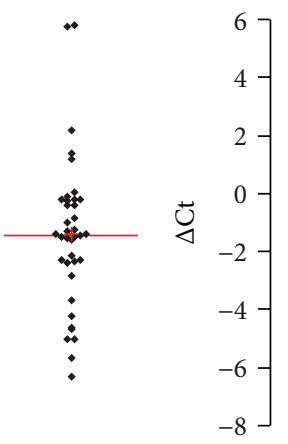

(a)

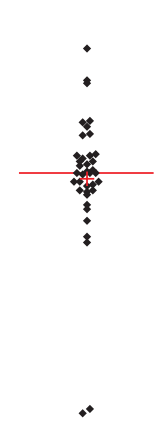

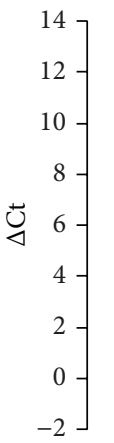

$\mathrm{T} 2$

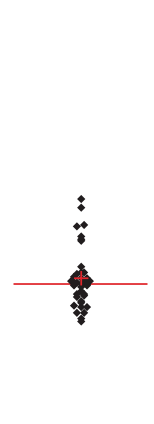

$\mathrm{T} 2$

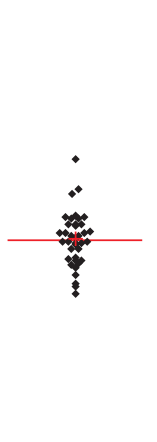

$\mathrm{T} 3$

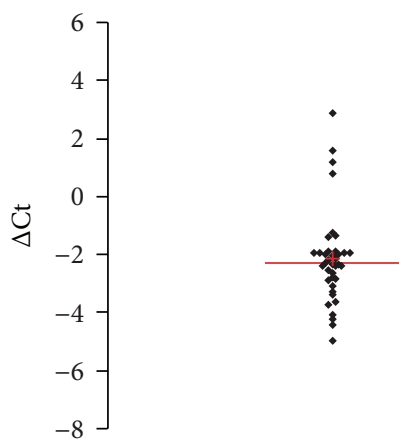

T3

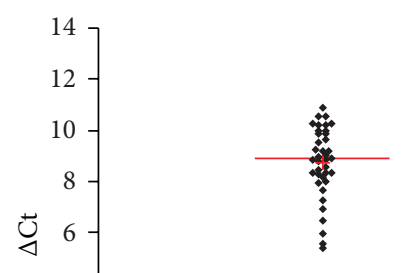

(b)

$\left.\begin{array}{r}4 \\ 2 \\ 0 \\ -2\end{array}\right]$

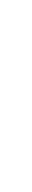

Figure 6: Normalized Ct $(\Delta \mathrm{Ct})$ of miR-21 (Panel a) and miR-141 (Panel b) in serum from patients with localized prostate cancer. T0: preoperative time; T1: 1st postoperative day; T2: 5 th postoperative days; T3: 30 th postoperative day.

to assess the expression of circulating miR-21 in serum samples from patients with different types of cancer, but without including prostate cancer because of too few cases [30]. By use of real-time quantitative reverse transcription-PCR, a marked overexpression of circulating miR-21 in 174 patients with solid cancers (breast, esophageal, gastric, colorectal, and lung cancers) with respect to 39 normal control subjects was assessed. Furthermore, miR-21 proved to be associated with the expression of genes that regulated inflammation [31]. miRNAs role in the development, maturation, and function of cells involved in the innate and adaptive immunity has been proved $[32,33]$. Chen et al. analyzed the frequent deregulation of serum miRNAs in patients with lung or colorectal carcinoma: they found a quite large portion (38.5\%) of the same shared members to be overexpressed also in serum samples from patients with type II diabetes. This is probably attributable to the inflammatory reactions occurring in all the samples under investigation [34]. Thus, although a set of miRNAs specifically associated with inflammation has been characterized [33], the involvement of other members may be hypothesized and still unreported.

miR-141 is representative of epithelial tissue; thus, its expression is not restricted to prostatic epithelium: nonetheless, circulating miR-141 levels in prostate cancer patients were successfully used to screen for metastatic prostate cancer with high sensitivity [6]. Virtually all epithelial cancers overexpress miR-141 (data from literature are mainly available for breast, lung, colon, and prostate cancers) [35]. The convergent deregulation of miR-141 in epithelial cancers suggests that the diagnostic performance of miR-141 in prostate cancer remains to be assessed. Furthermore, miR-141 has been shown to target p38 $\alpha$, thus modulating the oxidative stress response and ultimately affecting tumorigenesis [36].

In the present study, miR-21 and miR-141 levels did not show significant difference with preoperative values $(P>$ $0.05)$ in the first postoperative day. In contrast, a significant increase of both miR-21 and miR-141 was detected at the 5th postoperative day, with respect to the preoperative time. This finding is probably attributable to systemic inflammatory reactions occurring after surgery. We hypothesize that these alterations do not appear immediately at $\mathrm{T} 1$ because of a de novo production of miRNA from other body districts. At T3, the serum levels of miR-21 and miR-141 decreased to values comparable to preoperative time $(P>0.05)$.

Our findings on serum miR-141 seem to be in contrast with previous data in the literature. So far, miR-141 has been mainly associated with prostate cancer progression $[6,37-$ 39]. The expression levels of circulating miRNAs in low-risk, high-risk, and metastatic castration resistant prostate cancer (mCRPC) have highlighted the characteristic overexpression of miR-141 in mCRPC compared with low-risk disease [40]. On the contrary, our analysis has been conducted on serum samples from patients with localized prostate cancer. Moreover, other discrepancies about circulating levels of 

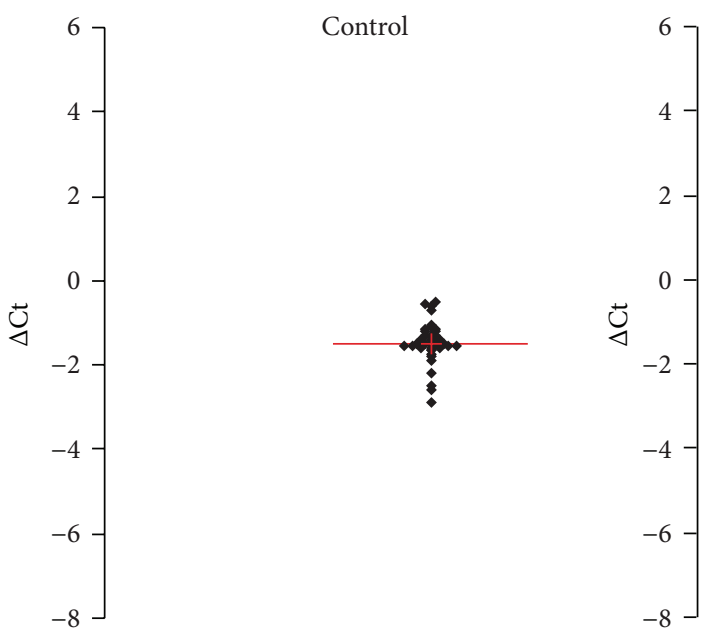

(a)

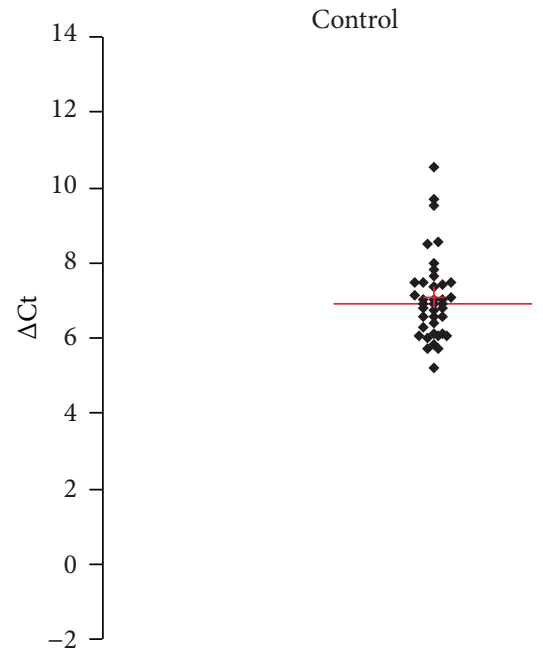

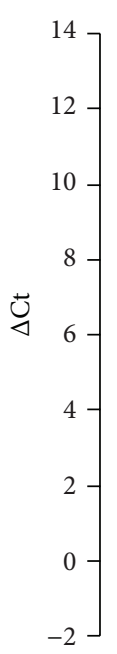

T0

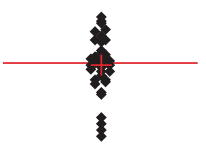

T0

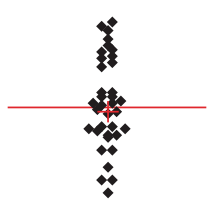

(b)

FIgURe 7: Normalized Ct $(\Delta \mathrm{Ct})$ of miR-21 (Panel a) and miR-141 (Panel b) in sera from patients with localized prostate cancer with respect to controls. T0: preoperative time; C: control.

miR-141 in prostate cancer have been reported by other researchers. As an example, Agaoglu and colleagues [41] did not find significant differences in circulating levels of miR141 in prostate cancer (both localized and advanced diseases) with respect to healthy controls. Furthermore, Mahn and coworkers [42] were unable to detect serum miR-141 in localized prostate cancer: the authors hypothesized that this event is due to their patient selection criteria (they did not include patients with metastatic prostate cancer) and to the the lack of a preamplification step to enrich for miRNAs, which was instead performed by Mitchell [6].

Similarly to miR-141, the overexpression of miR-21 has been mainly examined in advanced cancers [43, 44]. A recent study aimed at identifying circulating miRNAs able to discriminate mCRPC from localized prostate cancer revealed a statistically significant upregulation of miR-21 in the former group [45]. On the other hand, Folini [46] found similar expressions of miR-21 in localized tumor and surrounding healthy tissue specimens from 36 patients who undergone radical prostatectomy. In summary, while the upregulation of miR-21 and miR-141 has been established in metastatic prostate cancer, their modulation in localized forms is still controversial. To our knowledge, our report is the first to make serial postoperative measurements of serum miRNAs and analysis of their postoperative kinetics. Single postoperative measurements were successfully performed by other authors, both in prostate cancer patients [42] and in other malignancies [47]. Our results were quite surprising, since both serum miR-21 and miR-141 increased significantly at 5th postoperative day to finally return to the preoperative levels. The observed fluctuations could be explained by a de novo synthesis of miRNAs, suggesting their involvement in postsurgical inflammation.

\section{Conclusions}

Our study provided innovative information about postoperative changes in the levels of circulating microRNAs and 

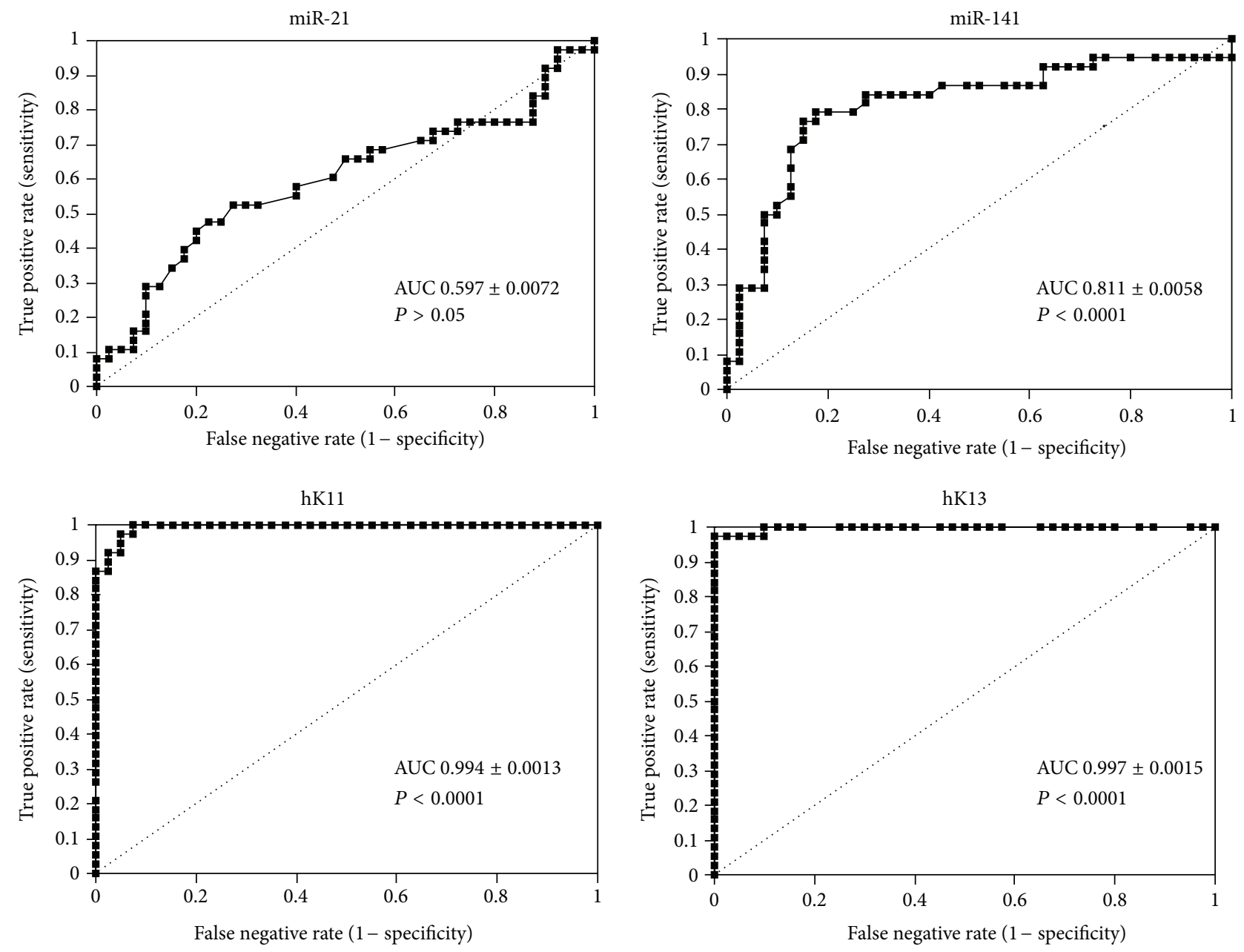

\begin{tabular}{ccccccccc}
\hline T0 versus control & miR-21 & SE & miR-141 & SE & hK11 & SE & hK13 & SE \\
\hline AUC & 0.597 & & 0.811 & & 0.994 & & 0.997 & \\
Sensitivity & 0.526 & 0.0072 & 0.789 & 0.0058 & 1 & 0.0013 & 0.974 & 0.0015 \\
Specificity & 0.725 & & 0.825 & & 0.925 & & 1 & \\
95\% CI & $0.471-0.723$ & $0.712-0.911$ & $0.97-1$ & & $0.973-1$ \\
\hline
\end{tabular}

FIGURE 8: ROC curves and AUCs of serums miR-21, miR-141, hK11, and hK13 between patients (T0) and healthy controls.

kallikreins. This was possible through serial samplings up to 30 days after surgery.

Our results assessed that the interest regarding kallikreins should not be restricted to PSA, since both hK11 and hK13 showed a marked correlation with prostate disease. Indeed, serums hK11 and hK13 showed a statistically significant decrease after surgery, although they did not fall down to zero such as PSA. The delayed increase in expression of serums miR-21 and -141 at the 5th postoperative day could be due to a de novo miRNA synthesis induced by systemic inflammatory reactions. At the 30th postoperative day, serums miR-21 and miR-141 were similar to preoperative values. Overall, the results here obtained confirmed that every change in expression of serum markers after surgery should always be taken with caution and confirmed by multiple observations. The diagnostic performance of the markers under examination needs to be confirmed by larger scale studies.

\section{Acknowledgements}

This research project was supported by 2007-2013 ESF "Competitiveness and Employment objective" Umbrian Regional Operational Programme (ROP), Avviso pubblico aiuti individuali per la realizzazione di progetti di ricerca.

\section{References}

[1] E. P. Diamandis, G. M. Yousef, A. R. Soosaipillai, and P. Bunting, "Human kallikrein 6 (zyme/protease M/neurosin): a new serum biomarker of ovarian carcinoma," Clinical Biochemistry, vol. 33, no. 7, pp. 579-583, 2000.

[2] C. V. Obiezu, A. Scorilas, D. Katsaros et al., "Higher human kallikrein gene 4 (KLK4) expression indicates poor prognosis of ovarian cancer patients," Clinical Cancer Research, vol. 7, no. 8, pp. 2380-2386, 2001. 
[3] G. M. Yousef, A. Scorilas, K. Jung, L. K. Ashworth, and E. P. Diamandis, "Molecular cloning of the human kallikrein 15 gene (KLK15). Up-regulation in prostate cancer," Journal of Biological Chemistry, vol. 276, no. 1, pp. 53-61, 2001.

[4] D. P. Bartel, "microRNAs: genomics, biogenesis, mechanism, and function," Cell, vol. 116, no. 2, pp. 281-297, 2004.

[5] B. P. Lewis, C. B. Burge, and D. P. Bartel, "Conserved seed pairing, often flanked by adenosines, indicates that thousands of human genes are microRNA targets," Cell, vol. 120, no. 1, pp. 15-20, 2005.

[6] P. S. Mitchell, R. K. Parkin, E. M. Kroh et al., "Circulating microRNAs as stable blood-based markers for cancer detection," Proceedings of the National Academy of Sciences of the United States of America, vol. 105, no. 30, pp. 10513-10518, 2008.

[7] G. A. Calin, C. Sevignani, C. D. Dumitru et al., "Human microRNA genes are frequently located at fragile sites and genomic regions involved in cancers," Proceedings of the National Academy of Sciences of the United States of America, vol. 101, no. 9, pp. 2999-3004, 2004.

[8] K. P. Porkka, M. J. Pfeiffer, K. K. Waltering, R. L. Vessella, T. L. J. Tammela, and T. Visakorpi, "MicroRNA expression profiling in prostate cancer," Cancer Research, vol. 67, no. 13, pp. 6130-6135, 2007.

[9] "Profiling of microRNA in serum/plasma and other biofluidsGuidelines for the miRCURY LNATM Universal RT microRNA PCR System, 3rd edition," http://www.exiqon.com/ .

[10] E. Mearini, E. Cottini, G. Cochetti, C. Antognelli, and V. Talesa, "Biomarkers of prostate cancer. A review," Minerva Urologica e Nefrologica, vol. 62, no. 2, pp. 163-178, 2010.

[11] E. P. Diamandis and G. M. Yousef, "Human tissue kallikreins: a family of new cancer biomarkers," Clinical Chemistry, vol. 48, no. 8, pp. 1198-1205, 2002.

[12] G. Sotiropoulou, V. Rogakos, T. Tsetsenis et al., "Emerging interest in the Kallikrein gene family for understanding and diagnosing cancer," Oncology Research, vol. 13, no. 6-10, pp. 381391, 2002.

[13] I. P. Michael, G. Pampalakis, S. D. Mikolajczyk, J. Malm, G. Sotiropoulou, and E. P. Diamandis, "Human tissue kallikrein 5 is a member of a proteolytic cascade pathway involved in seminal clot liquefaction and potentially in prostate cancer progression," Journal of Biological Chemistry, vol. 281, no. 18, pp. 12743-12750, 2006.

[14] C. Becker, T. Piironen, K. Pettersson et al., "Discrimination of men with prostate cancer from those with benign disease by measurements of human glandular kallikrein 2 (HK2) in serum," Journal of Urology, vol. 163, no. 1, pp. 311-316, 2000.

[15] A. J. Vickers, A. M. Cronin, G. Aus et al., "A panel of kallikrein markers can reduce unnecessary biopsy for prostate cancer: data from the European Randomized Study of Prostate Cancer Screening in Göteborg, Sweden," BMC Medicine, vol. 6, p. 19, 2008.

[16] X. Bi, H. He, Y. Ye et al., "Association of TMPRSS2 and KLK11 gene expression levels with clinical progression of human prostate cancer," Medical Oncology, vol. 27, no. 1, pp. 145-151, 2010.

[17] A. Chang, G. M. Yousef, A. Scorilas et al., "Human kallikrein gene 13 (KLK13) expression by quantitative RT-PCR: an independent indicator of favourable prognosis in breast cancer," British Journal of Cancer, vol. 86, no. 9, pp. 1457-1464, 2002.

[18] K. M. Nelson and G. J. Weiss, "microRNAs and cancer: past, present, and potential future," Molecular Cancer Therapeutics, vol. 7, no. 12, pp. 3655-3660, 2008.
[19] J. W. F. Catto, A. Alcaraz, A. S. Bjartell et al., "MicroRNA in prostate, bladder, and kidney cancer: a systematic review," European Urology, vol. 59, no. 5, pp. 671-681, 2011.

[20] C. H. Lawrie, S. Gal, H. M. Dunlop et al., "Detection of elevated levels of tumour-associated microRNAs in serum of patients with diffuse large B-cell lymphoma," British Journal of Haematology, vol. 141, no. 5, pp. 672-675, 2008.

[21] N. Kosaka, H. Iguchi, and T. Ochiya, "Circulating microRNA in body fluid: a new potential biomarker for cancer diagnosis and prognosis," Cancer Science, vol. 101, no. 10, pp. 2087-2092, 2010.

[22] A. E. Szafranska, T. S. Davison, J. John et al., "MicroRNA expression alterations are linked to tumorigenesis and nonneoplastic processes in pancreatic ductal adenocarcinoma," Oncogene, vol. 26, no. 30, pp. 4442-4452, 2007.

[23] D. Lebanony, H. Benjamin, S. Gilad et al., "Diagnostic assay based on hsa-miR-205 expression distinguishes squamous from nonsquamous non-small-cell lung carcinoma," Journal of Clinical Oncology, vol. 27, no. 12, pp. 2030-2037, 2009.

[24] H. Benjamin, D. Lebanony, L. Cohen et al., "Differential diagnosis of mesothelioma using a microRNA assay," in Proceedings of the 44th American Society of Clinical Oncology Annual Meeting, Chicago, Ill, USA, June 2008, Abstract 22000.

[25] N. Rosenfeld, R. Aharonov, E. Meiri et al., "microRNAs accurately identify cancer tissue origin," Nature Biotechnology, vol. 26, no. 4, pp. 462-469, 2008.

[26] F. J. Sheedy and L. A. J. O’Neill, “Adding fuel to fire: microRNAs as a new class of mediators of inflammation," Annals of the Rheumatic Diseases, vol. 67, supplement 3, pp. iii50-iii55, 2008.

[27] S. Zhu, M. Si, H. Wu, and Y. Mo, "MicroRNA-21 targets the tumor suppressor gene tropomyosin 1 (TPM1)," Journal of Biological Chemistry, vol. 282, no. 19, pp. 14328-14336, 2007.

[28] F. Meng, R. Henson, H. Wehbe-Janek, K. Ghoshal, S. T. Jacob, and T. Patel, "MicroRNA-21 regulates expression of the PTEN tumor suppressor gene in human hepatocellular cancer," Gastroenterology, vol. 133, no. 2, pp. 647-658, 2007.

[29] Z. Zhang, Z. Li, C. Gao et al., "miR-21 plays a pivotal role in gastric cancer pathogenesis and progression," Laboratory Investigation, vol. 88, no. 12, pp. 1358-1366, 2008.

[30] B. Wang and Q. Zhang, "The expression and clinical significance of circulating microRNA-21 in serum of five solid tumors," Journal of Cancer Research and Clinical Oncology, vol. 138, no. 10, pp. 1659-1666, 2012.

[31] F. Wu, M. Zikusoka, A. Trindade et al., "microRNAs are differentially expressed in ulcerative colitis and alter expression of macrophage inflammatory peptide-2 alpha," Gastroenterology, vol. 135, no. 5, pp. 1435-1438, 2008.

[32] M. P. Gantier, A. J. Sadler, and B. R. G. Williams, "Fine-tuning of the innate immune response by microRNAs," Immunology and Cell Biology, vol. 85, no. 6, pp. 458-462, 2007.

[33] R. M. O'Connell, D. S. Rao, A. A. Chaudhuri, and D. Baltimore, "Physiological and pathological roles for microRNAs in the immune system," Nature Reviews Immunology, vol. 10, no. 2, pp. 111-122, 2010.

[34] X. Chen, Y. Ba, L. Ma et al., "Characterization of microRNAs in serum: a novel class of biomarkers for diagnosis of cancer and other diseases," Cell Research, vol. 18, no. 10, pp. 997-1006, 2008.

[35] J. Lu, G. Getz, E. A. Miska et al., "MicroRNA expression profiles classify human cancers," Nature, vol. 435, no. 7043, pp. 834-838, 2005.

[36] B. Mateescu, L. Batista, M. Cardon et al., "MiR-141 and miR200a act on ovarian tumorigenesis by controlling oxidative 
stress response," Nature Medicine, vol. 17, no. 12, pp. 1627-1635, 2011.

[37] J. C. Brase, M. Johannes, T. Schlomm et al., "Circulating miRNAs are correlated with tumor progression in prostate cancer," International Journal of Cancer, vol. 128, no. 3, pp. 608616, 2011.

[38] L. A. Selth, S. Townley, J. L. Gillis et al., "Discovery of circulating microRNAs associated with human prostate cancer using a mouse model of disease," International Journal of Cancer, vol. 131, no. 3, pp. 652-661, 2012.

[39] R. J. Bryant, T. Pawlowski, J. W. F. Catto et al., "Changes in circulating microRNA levels associated with prostate cancer," British Journal of Cancer, vol. 106, no. 4, pp. 768-774, 2012.

[40] H. C. Nguyen, W. Xie, M. Yang et al., "Expression differences of circulating microRNAs in metastatic castration resistant prostate cancer and low-risk, localized prostate cancer," The Prostate, vol. 73, no. 4, pp. 346-354, 2013.

[41] F. Y. Agaoglu, M. Kovancilar, Y. Dizdar et al., "Investigation of miR-21, miR-141, and miR-221 in blood circulation of patients with prostate cancer," Tumor Biology, vol. 32, no. 3, pp. 583-588, 2011.

[42] R. Mahn, L. C. Heukamp, S. Rogenhofer, A. Von Ruecker, S. C. Müller, and J. Ellinger, "Circulating microRNAs (miRNA) in serum of patients with prostate cancer," Urology, vol. 77, no. 5, pp. 1265-e16, 2011.

[43] F. Meng, R. Henson, M. Lang et al., "Involvement of human micro-RNA in growth and response to chemotherapy in human cholangiocarcinoma cell lines," Gastroenterology, vol. 130, no. 7, pp. 2113-2129, 2006.

[44] P. E. Blower, J. Chung, J. S. Verducci et al., "microRNAs modulate the chemosensitivity of tumor cells," Molecular Cancer Therapeutics, vol. 7, no. 1, pp. 1-9, 2008.

[45] A. Watahiki, R. J. Macfarlane, M. E. Gleave et al., "Plasma miRNAs as biomarkers to identify patients with castrationresistant metastatic prostate cancer," International Journal of Molecular Sciences, vol. 14, no. 4, pp. 7757-7770, 2013.

[46] M. Folini, P. Gandellini, N. Longoni et al., "miR-21: an oncomir on strike in prostate cancer," Molecular Cancer, vol. 9, p. 12, 2010.

[47] H. Konishi, D. Ichikawa, S. Komatsu et al., "Detection of gastric cancer-associated microRNAs on microRNA microarray comparing pre- and post-operative plasma," British Journal of Cancer, vol. 106, no. 4, pp. 740-747, 2012. 

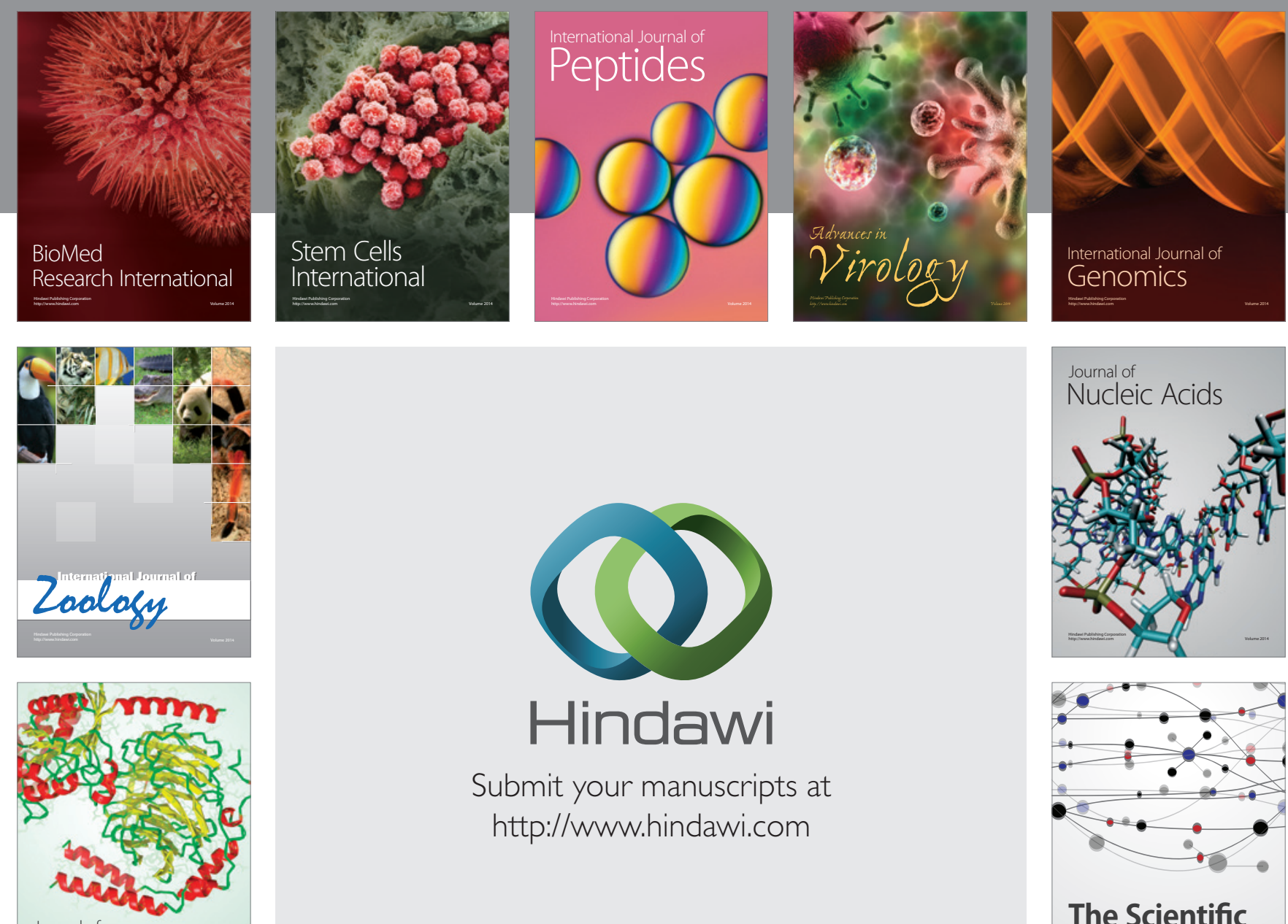

Submit your manuscripts at

http://www.hindawi.com

Journal of
Signal Transduction
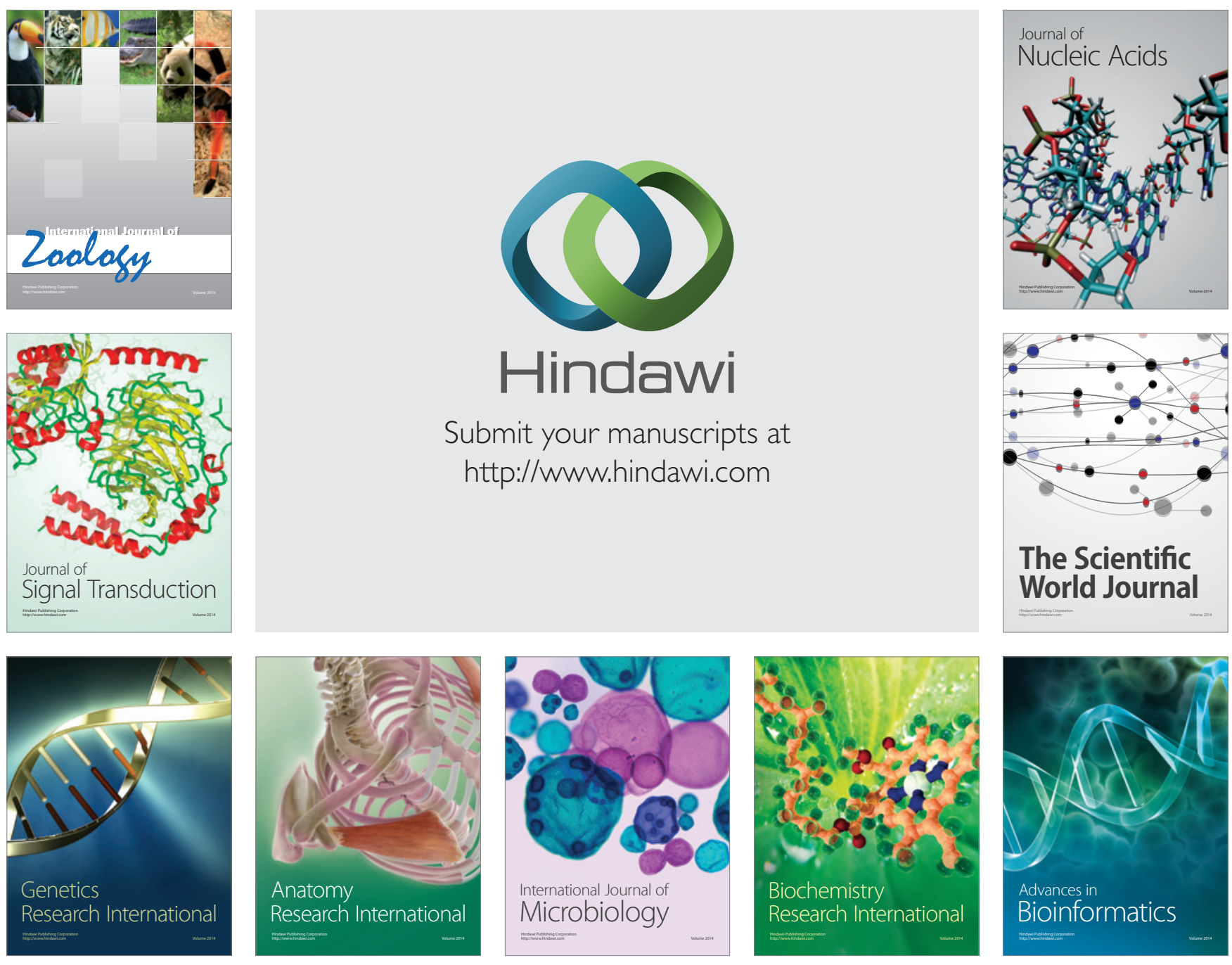

The Scientific World Journal
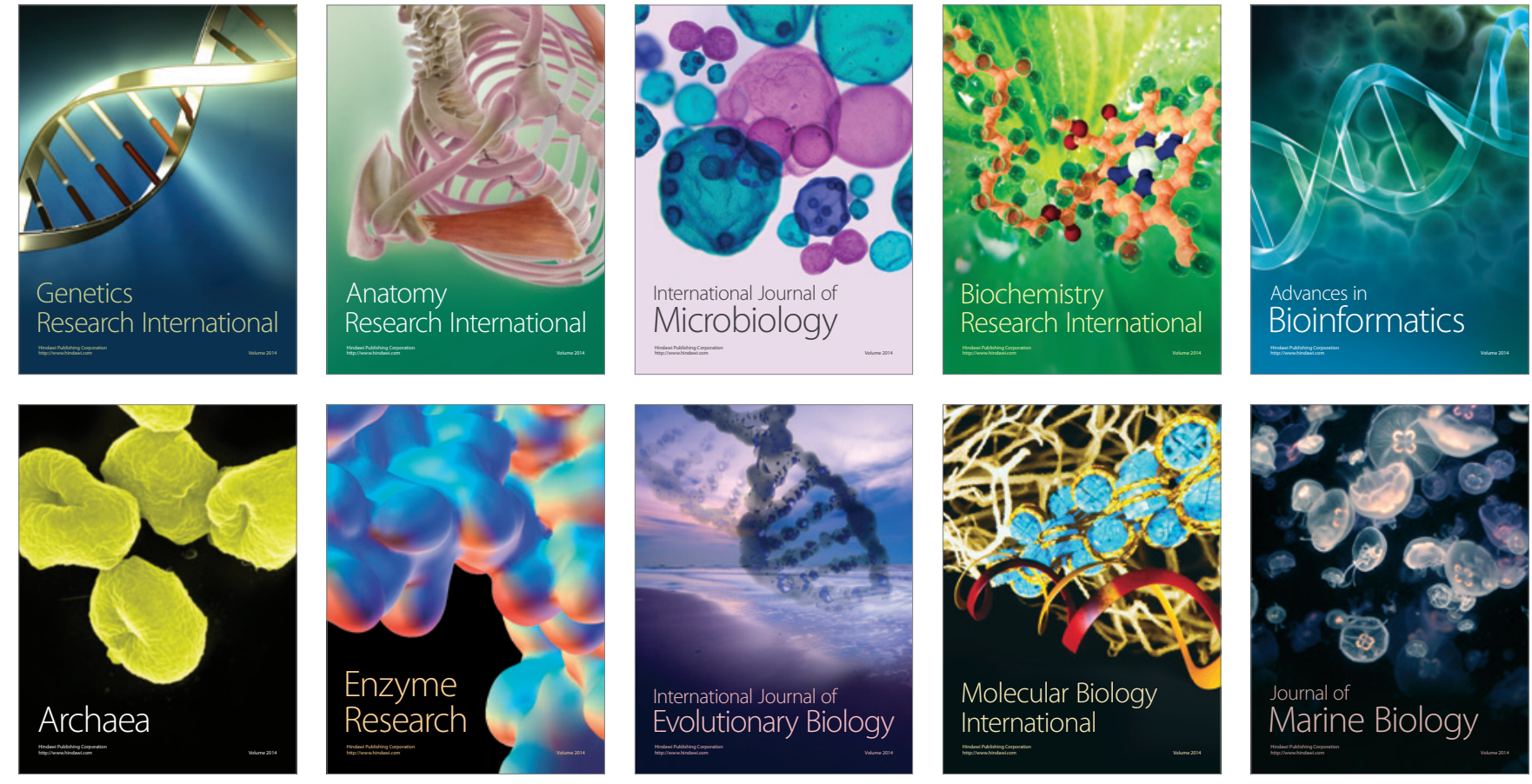